\title{
The Role of Leadership and its Effect on the Temporal Patterns of Global Software Development Teams
}

\author{
Ian Broooks \\ Computer Science and Engineering \\ University of North Texas \\ Denton, Texas, USA \\ ibrooks@gmail.com
}

\author{
Kathleen Swigger \\ Computer Science and Engineering \\ University of North Texas \\ Denton, Texas, USA \\ kathy@cs.unt.edu
}

\begin{abstract}
Drawing on previous work, the authors explore the role of leaders and their effect on the temporal communication patterns of global software student project teams. Archived group interactions captured during the course of two virtual team projects involving students in the US, Panama, and Turkey were analyzed using a content analysis scheme derived from a collaboration theory that captures communication behavior associated with teams in virtual environments. Results from these analyses suggest that although teams with leaders have many more communications throughout a project, they have similar temporal patterns as compared to teams without leaders. However, the proportion of the different communication behaviors varies considerably between leader and leaderless teams as well as between leaders and their "followers." More specifically, analysis demonstrated how variation in temporal patterns for leaders and their followers were different from those team members with no leader, thereby bolstering the argument for developing and testing temporal measures in group research.
\end{abstract}

Keywords - leadership; virtual team; distributed learning; computer-mediated communication; temporal analysis

\section{INTRODUCTION}

The idea that teams work in cycles is a prominent theme throughout the literature on groups and team performance [1]. Moreover, this same literature has associated various activities with specific temporal phases or stages within a team project [2]. Even though globally distributed teams may find it more difficult to follow a temporal cycle [3], they, nevertheless, do experience similar types of activity patterns [4]. Unlike faceto-face teams, globally distributed teams must balance a number of temporal challenges that demand complex and dynamic coordination, management, and synchronization (e.g., Hamm, [5]). Meeting these challenges requires a leader who understands how to manage the temporal resources of a team [6]. In spite of this recent discovery, research on how leaders actually affect the temporal patterns of a global team is scarce. Although leadership researchers have made explicit links between temporally related activities and the leadership role [7], the formal use of temporal variables in creating specific relationships between leaders and the temporal patterns of a team is still scarce and scattered [8].
The main objective of the study, therefore, is to determine the impact of leaders on the temporal communication patterns of global software development student teams. We chose to study global software development teams because they represent an activity that demands a relatively large number of people engaging in a complex process that is punctuated by intense periods of group communication, negotiations, and shared agreements. Although major parts of a software project can be completed as small programs (e.g., Parnas, [9]), the individual components must, at some point, come together into a single application. Thus temporal coordination among various team members is critical to the success of a large software project [10].

The major focus of the study is on the role of leadership and how it affects the temporal patterns of the global software development process. In order to discover these temporal patterns, we use a content analysis technique to define specific communication behaviors that occur in global software development teams. These behaviors are then used to analyze and compare the time variant patterns of teams with and without leaders. Data was gathered from two global software development projects that took place in spring 2009 and fall 2010. Students enrolled in courses at the University of North Texas, Universidad Tecnológica de Panamá, and Atılım University were asked to develop a large software product, using only collaborative technologies to communicate with one another. Text generated from these projects were then "content analyzed" and used to explain the time variant patterns of student programming teams with and without a leader. The two major questions asked in this paper are: First, do teams with leaders have different temporal cycles than teams without leaders? Second, how do the temporal behaviors of leaders differ from their fellow teammates and from students in teams without leaders? By applying a content analysis technique to the transcripts of global software development teams, we are able to measure and visualize the time variation of different types of communication behaviors that occur during the different stages of the software development process.

Our initial hypothesis is that the variations in both type and number of team communications will provide an understanding of the role of leadership in teams. We theorize that the number 
and types of communication behaviors will vary over time and that this variation will be different for teams with leaders as opposed to those without. This is consistent with the results of our previous research, which show that global software development teams, in general, follow a two-stage temporal communication behavior pattern [11][12]. In a second study, we found clear differences between the performance of teams with leaders as opposed to those teams without leaders [13]. Teams with leaders scored higher on team assignments than those teams that had no clear leader. Findings from these two studies led us to wonder how exactly leaders affect the temporal patterns of their teams and whether specific temporal communication patterns can be associated with leaders as opposed to other members of the team. If this is the case, then we should be able to develop a model of effective team leadership that shows what and when specific communication behaviors should occur within a global software development project.

Although this study takes place within the context of global virtual software teams, we believe its results have implications for teams in general. The various methods that have been used can be applied to other types of global teams. Knowledge obtained from this study should provide insight into current empirical research on leadership and how the communication patterns of leaders affect the temporal patterns of a team. A second area of potential application is in the teaching of distributed learning courses. As the number of online courses increases, teachers need to become aware of how the presence (or absence) of a leader can impact a student group's performance. More detailed information about the temporal rhythms of global virtual teams should contribute to the improvement of our overall understanding of how students and industry personnel use distributed technology to work together. Finally, qualitative and quantitative analysis of the data collected about when and how leaders interact with their teams should provide information about how an online web-based tool can help global virtual teams coordinate required tasks more effectively.

The paper begins by providing a research framework for studying leadership and its role in virtual teams. We then describe the research methods, which includes a description of the student projects. We examined the temporal communication patterns of teams in two different on-line global software development projects. The projects were assigned similar tasks and used similar collaborative software tools. The paper then presents the research findings and concludes with a discussion of how these results can be used to improve our understanding of how leadership communication temporal behaviors can affect teams.

\section{REVIEW OF RELATED RESEARCH}

The research literature has consistently reported that successful team outcomes depend on a team's ability to interact with one another over the course of a task, project, or activity [14]. Moreover, studies that examine team communication show that the interactions have a temporal nature that is both unique and cyclical [15] . To characterize these interactions, researchers have coined the phrase temporal patterning, which describes the rhythms by which teams synchronize or coordinate their activities [16][17]. But there are a number of different ways to define a group's temporal rhythms. There are a team member's individual time preferences such as urgency [18], pace [19], and rhythm [20]. There is also the use of more global time perspectives such as clock time or seasons of the year [21] The "entrainment" perspective developed by McGrath and Hollingshead [22] and elaborated by Ancona and Chong [23] and Bluedorn [8] is still another aspect of time that affects group work. The entrainment dimension has been used to explain how individuals align their everyday lives to internal and external forces [24]. For example, a team member quickly learns to balance work-related temporal factors such as job deadlines, organizational culture, etc., with those that compete with their personal lives such as a child's school or play routine [25]. In the same way that an individual's work cycle gets interrupted every time a child gets sick, a team member can experience similar disruptions if a virtual meeting occurs outside her regular work hours [26]. Whenever an individual's work-cycle becomes disrupted, the orderliness of team interactions (communicative, decisional, and interpersonal behaviors) is altered [27].

All this suggests that effectively managing team interaction behaviors is of paramount importance to the success of any team. This is particularly true in globally distributed teams that must find workable substitutions for temporally coordinating interactions and flows of information [22]. Whereas synchronous teams have the luxury of allowing temporal patterns to emerge spontaneously, research suggests that working in a virtual environment requires explicit attention to issues of temporal coordination [3]. Thus, the importance of leaders who can influence team processes and outcomes for globally distributed teams is a significant factor that can lead to team success [28]. A significant role for the leader is to act as a "completer" [29], that is, someone who continually urges the group to stay on task and work towards goals. In addition to task related functions, the leader also provides moral support to the group and encouragement when members are slow to produce [30].

The research literature defines leadership within distributed teams as being either designated and/or emergent [31]. Emergent leaders are those individuals who are selected by members of the group, as opposed to leaders who are designated by someone in authority [31]. Empirical studies of designated leaders of distributed teams indicate that effective leaders are those individuals who mentor teammates, empathize with individuals, assert their authority, and provide regular, detailed, and prompt communication [32]. A second study found that effective designated leaders were those who pressured teams about task demands and showed awareness and consideration of others early in the project [33].

Leaders have been similarly characterized in the research on emergent leaders [34]. For example, Yoo and Alavi [35] studied emergent leaders in groups of executives enrolled in an on-line business class and found that the emergent leaders initiated more and longer messages. Moreover, the messages sent by emergent leaders were more likely to contain content related to the task functions of initiating, scheduling, and integrating activities. Misiolek and Heckman [36] also 
examined emergent leaders and found that there were two different patterns of emergent leadership behavior: strong or centralized in one individual and weak or distributed across different individuals. Distributed leaders tended to initiate and receive more social and task related communication than centralized leaders.

The fact that many of the studies about leadership (cited above) used students as subjects suggests that leadership is also important in distributed learning teams. The ability to work efficiently and effectively with others in a group is not merely important to a student's success; it is essential [37]. As a result, science and engineering schools are rapidly increasing the number of courses that involve students from other countries and cultures [38]. Teachers of software engineering have been particularly eager to incorporate courses that allow students to experience many of the real-world projects that simulate the distributed software development process [38] [39]. When students are assigned globally distributed projects, issues of leadership and group process inevitably arise. Some researchers argue that these global student teams often reflect many of the same characteristics of emergent leader teams because they exist for only a limited amount of time and the team members generally have no prior experience working with one another [36]. The students in global teams may formally appoint a single leader, but often this never occurs, and the group members eventually end up completing the required tasks in an ad-hoc manner. As a result, Lim and Chidambaram suggest that the followers in distributed learning teams need to become more proactive and self-starters if they want to realize success [40].

The studies cited above explore different effects of leadership on the temporal patterns of globally distributed teams. While these studies suggest possible links between temporal patterns and leadership, none explicitly address the question of how a leader may affect the temporal patterns of a team. Most real-world team projects have phases or milestones that require different types of coordination and synchronization. For example, the software development life cycle generally contains different stages for eliciting requirements, designing, coding, and testing [41]. Recent studies suggest that an effective leader can provide a temporal coordination mechanism that can reduce the time devoted by the team to process management issues and make communicative behaviors (the conveyance of ideas) more efficient [34]. Maintaining this coordination structure throughout the length of a project should not only stimulate greater levels of participation among members but also lead to greater success [42]. Thus it follows that an effective leader is one who can coordinate and match the team's various communication behaviors to the different phases of a project. In the case of global software development, the leader should try to match the team's communication behavior to the different stages in the software development life cycle. In order to address this issue, we try to determine if communication in teams with leaders has a different temporal pattern than those teams without leaders. We also explore the question of whether a team leader has different temporal communication behaviors than the followers in the teams with leaders. We also try to break down the leadership functions that occur in the different phases of a software development project and determine whether they are unique or similar to teams without leaders.

\section{RESEARCH METHODOLOGY FOR THE STUDY}

To investigate leadership issues related to temporal patterns in global software teams, we carried out a study of distributed teams with members located in three different sites (Turkey, US, and Panama). As will be described in more detail in Section III, the subjects of this study were all students, but the tasks were similar to those found in most companies that are doing distributed software development. The projects lasted between four to six weeks, which is a typical length for a senior level programming project. Students enrolled in the courses received around $30 \%$ credit as part of their overall grade for the course, although additional incentives were provided in the form of prizes, t-shirts, and certificates.

\section{A. Students and Team Configuration}

A total of 114 students from three campuses (Atrlim University (Turkey), University of North Texas (US), or Universidad Tecnologica de Panama, Panama) participated in one of two projects. There were a total of 60 students in the first project and 54 students in the second project. All students were enrolled in either a junior-senior level computer science or information technology course at their respective universities. The average age of the participants was 19.5 years. There were no significant differences between the students in the two projects in terms of grades assigned to the projects $(t=-$ $1.18, p=.27)$, grade point average (GPA) $(t=-0.15, p=.87)$ or programming experience $(t=-0.52, p=.60)$. Students were randomly assigned to one of 12 teams in the first project, and one of 10 teams in the second project. Total team size varied between six and nine members, each team having between 2 or 3 students from each country.

Although the students indicated no previous experience with distributed projects, most $(99 \%)$ had worked on at least one team project at their universities. The language for communication among all team members was English. There was an eight hour difference between Turkey-based and USbased students and a seven hour difference between Turkish and Panamanian students. The US-based students were one hour ahead of the Panama-based students.

Prior to the course assignment, students received instruction on the course management system (CMS) that was used throughout the project and on team effectiveness. At the beginning of each project, students were encouraged to elect or nominate a team leader. Other roles for team members were also suggested.

\section{B. Course Projects}

Students worked on one of two real-world projects. In each project, students were required to design, program and test applications for a particular client or industry. Both projects were complex and realistic in that they required students to talk about different requirements and/or programming issues. As in industry, the teams had a number of deliverables, including 
design documents, code, and test plans. These global software development projects were intended to proceed from requirements generation, detailed design, and a working prototype in a four to six week period. Although instructors gave suggested times for when the different sub-tasks should be completed, there were no firm dates for the individual deliverables. Student teams, however, were monitored throughout the project using special software that allowed instructors to view and/or discuss any issues or problems that might occur.

The programming assignment for Project 1 required teams to design, create and test software for managing a car rental system. The specific deliverables included a functional specification for the system, a design and implementation of a test database, SQL test queries, Java programs to test the system, and a final report. Project 1 was assigned to students during the fall semester of 2009 . The total length for this project was one month.

The programming assignment for Project 2 required students to design and develop a Book Store Management application that was located in Panama. Hence, students were asked to develop an interface that displayed "Spanish" text to the user. The bookstore application was to include various functions that would add/update/remove a bookstore's assets. The project was assigned to students in the spring semester of 2010. The total length for this project was six weeks.

\section{Communication Technology}

Students communicated with one another using a course management system software (CMS) called Sakai (Sakai, 2011). This particular CMS supports asynchronous communication tools such as forums, emails, file sharing, wiki discussion, etc., and synchronous communication such as chat, messaging, and conferencing. Several programs were written to support the recording and categorization of the group interactions that occurred within each team and project. All student interactions were automatically saved and time stamped when they occurred. For purposes of this study, a single communication activity was defined as a single asynchronous post to a forum, a message sent, or a synchronous chat message. After the projects were complete, the data was transferred to a database that served as the central repository for all data.

\section{Content Analysis and Leadership Selection}

In order to better understand the role of leadership in setting the temporal patterns of a distributed team, we applied a content analysis technique to all the students' communication activities in both projects. This process generally requires the application of a particular coding scheme that characterizes an online interaction. Since this project's main focus was on communication behaviors that occurred among team members, we chose a coding scheme that was designed to capture these types of activities [43].

The Curtis and Lawson instrument specifies five different levels of collaborative interactions or behaviors [43]. The planning behavior indicates that the message contains a statement that relates to organizing work, initiating activities, or group skills. The contributing code is assigned to messages that give help, provide feedback, exchange resources, share programming knowledge, etc. Other collaborative behaviors are also noted such as seeking input and reflection. Conversations about social matters that are unrelated to the group task at hand are generally placed in the social interaction category. Two trained coders categorized messages into the five behavioral categories. Percent agreement among the two coders for general content was $84.2 \%$. The application of this coding system to global software development transcripts is based on our prior research in applying these codes to the study of global software teams and related research in comparing group performance [12][11]. We refer the reader to these sources for a more detailed description and validation of our coding system and its application to the study of global software development student teams. A total of 2455 communication activities were coded for the two projects.

Once the data was coded, the student transmissions were analyzed to determine whether a leader emerged within a group. In order to do this, we looked at both the total number of transmissions as well as the content of the messages to determine if an individual really could be classified as a leader. A description of this process can be found in [13]. Through such a process, we were able to identify 13 groups with clear leaders (Leader Group), and 11 groups that had no identifiable leader (No-Leader Group).

The coded activities for each group were then sequenced in time. Since the total amount of time for each project differed (4 weeks versus 6 weeks), we also computed the communication activities that occurred during each percent of project completion; that is, dividing the total number of minutes per project by 100 and then adding up the totals for each communication behavior that occurred during each $1 \%$ period. This normalization procedure allows us to compare work patterns between the two projects. Through such a process we were able to compare the communication behaviors of groups with leaders and those with no leader.

\section{RESULTS}

We first looked at the communication activities of teams from both projects in order to examine when specific types of behaviors occurred during the projects. Fig. 1 illustrates the number of different types of communication activities that occurred over the length of the two projects for all student teams. To determine whether there were specific cycles of temporal patterns in the projects, we compared the proportion of communication behaviors that occurred in each category between each adjacent percent-of-project completion. For example, we compared the different proportions of communication behaviors that occurred in the first time period $(10 \%)$ with those that occurred in the second time period (20\%), and the proportions in the second time period $(20 \%)$ with those in the third time period (30\%), etc. This allowed us to find the variation in the communication patterns between one time period and another. Statistical analysis shows that there were significant communication pattern changes between the $40-50 \%$ time period $(P=0.0001$, Fisher's exact test $)$ and between the $70-80 \%$ time period $(P=0.002$, Fisher's exact 
test). The dotted lines in Fig. 1 mark the changes in communication patterns for the different time periods. Similar findings are reported in [44], and seem to suggest that the groups (as a whole) had communication patterns that were indeed cyclical and could correspond to the different software development stages of design, implementation, and testing. For example, the large number of planning behaviors in the first stage (10-40\%) of the project decreases in the second stage (40$70 \%$ ) as teams move from the design to the implementation phase. Similarly, contributing behaviors peak during the second stage, which also corresponds to the coding stage in the software development life-cycle. There is a slight increase in all communication activities towards the end of the project, but the increase is not significant as students try to finish their testing and documentation.

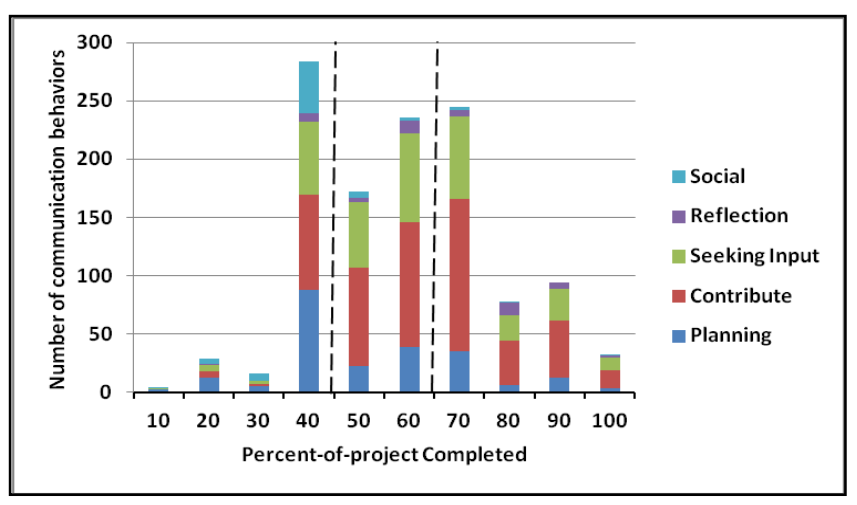

Figure 1. Temporal patterns of All teams

\section{A. Leader vs. No-Leader Temporal Patterns}

Given that that we discovered specific cycles in the temporal communication behaviors of all students in both projects, we tested whether teams with leaders had similar or different cyclical patterns than teams without leaders. Our initial hypothesis was that the teams with leaders would show marked temporal patterns similar to what was found in the combined data, and that these cycles would be different from the temporal patterns of No-Leader Groups. Figs. 2 and 3 show the temporal variation of communication activities for Leader and No-Leader teams. Again, comparing the number of communication behaviors that occurred in each category between each adjacent percent-of-project, we found that there is a significant pattern shift in the $40-50 \%$ and in the $50-60 \%$ time periods for teams with and without leaders. For Leader teams, differences occur at the $40-50 \%(P=0.00001$, Fisher's exact test $)$ and $50-60 \%(P=0.01$, Fisher's exact test $)$, For NoLeader teams, differences also occur at the 40-50\% $(P=0.002$, Fisher's exact test $)$ and $50-60 \%(P=.07$, Fisher's exact test $)$. Although the Leader teams had more communications in almost every time period, the actual temporal patterns for the different communication behavioral categories were quite similar to No-Leader groups. Correlations between each of the five temporal communication behaviors for the Leader and NoLeader teams were as follows: planning $(r=0.96)$, contributing $(r=0.80)$, seeking behavior $(r=0.78)$, and reflection $(r=$

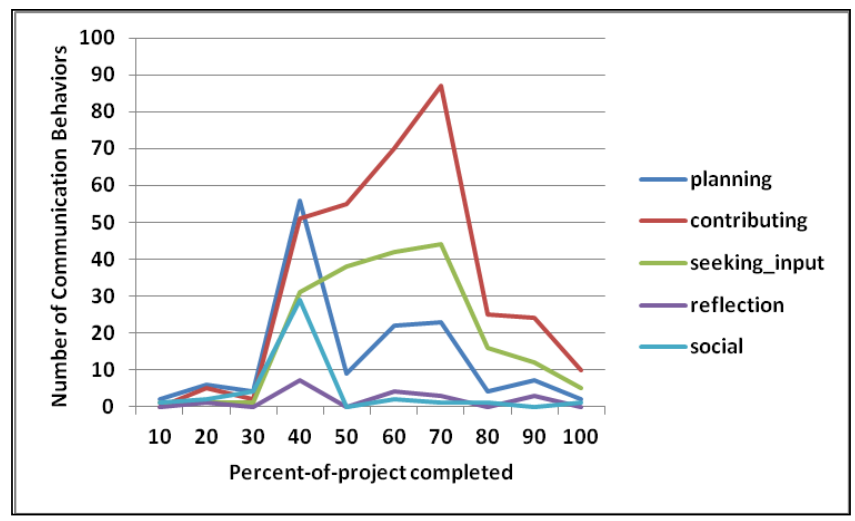

Figure 2. Temporal patterns of groups with leaders

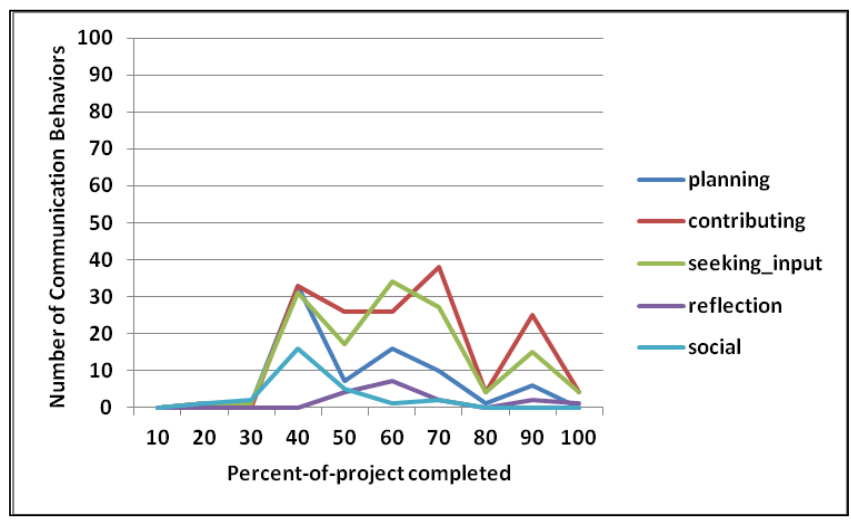

Figure 3. Temporal patterns of groups with No-leaders

$0.67)$, social interaction $(r=0.80)$. Only the reflection behaviors show no correlation, which was probably due to the low number of reflection behaviors for all groups.

This analysis of the data indicates that the teams with leaders had significantly more communication in each time period throughout the project $(10 \%-p<0.04 ; 20 \%-p<-.04$; $30 \%-p<0.04 ; 40 \%-p<0.01 ; 50 \%$ - $p<0.04 ; 70 \%-p<0.05$; $80 \%-p<0.05 ; 100 \%-p<0.05$ ), except the $60 \%$ and $90 \%$ time periods. However, the overall proportion temporal communication patterns for both Leader and No-leader teams were similar over the course of the project. These variations in the patterns of communication behaviors for both groups tend to show how both types of teams seem to follow the different phases of the software development life cycle, although obviously at different "rates." For example, both Leader and No-Leader teams have a higher proportion of planning behaviors at the beginning of the project, and a higher proportion of contributing behaviors in the middle and end periods. Social interaction seems to be higher at the beginning of the projects for both the Leader and No-leader teams. Although neither group showed a significant differences between the 70-80\% time period, a temporal difference that occurred in the combined data, the figures clearly show that both the Leader and No-Leader teams start to change their communication patterns toward the end of the project. Perhaps the individual data for both groups was insufficient to show significance in this time period. 


\section{B. Comparison of Proportion of Temporal Patterns}

Since both Leader and No-Leader teams tended to follow similar "overall" temporal cycles within their projects, we looked for other evidence to determine the differences between temporal behaviors of Leader versus No-Leader teams. Thus, we compared the proportion of the different behavior categories in Leader and No-Leader teams for each time period to determine if these variations might indicate differences (Figs. 4 and 5). Intuitively, one would expect that the teams with leaders would have a higher proportion of planning activities at the beginning of the project, and then gradually increase the proportions of contributing and seeking input communication behaviors during the next phases of the project. No-Leader teams, on the other hand, would start with a lower proportion of planning activities, and then gradually come to the realization that planning activities were important to the success of their projects.

To determine if our hypotheses were correct, we compared the proportion of communication behaviors that occurred in each time period for Leader and No-Leader teams. Statistical analysis showed differences between Leader and No-Leader teams at time periods $10 \%(P=0.00001$, Fisher exact test $)$, $40 \%(P=.05$, Fisher exact test $), 50 \%(P=0.0001$, Fisher exact test $)$, and $60 \%(P=0.03$, Fisher exact test $)$. Our instincts proved to be somewhat correct in that No-Leader teams failed to start quickly (i.e., actually, they did nothing until the $20 \%$ period), and that Leader teams had more planning activities (i.e., a higher proportion of planning behaviors) in the early stages of the project. The next critical differences appear to occur in the middle of the projects. At the $40 \%$ time period, the No-Leader teams had a higher proportion of seeking-input behaviors. On the other hand, Leader teams seem to be asking more questions and engaged in a higher proportion of contributing behaviors at the $50 \%$ time period, whereas the Non-Leader teams are planning and socializing. Finally, during the $60 \%$ period the No-Leader teams seem to be again seeking more input from one another and contributing less than the students in the Leader teams.

This data shows that there is proportional variation in the communication behaviors that occur in groups that have leaders as opposed to those that do not have a leader. As shown in Figs. 4 and 5, the ability to establish a shared vision

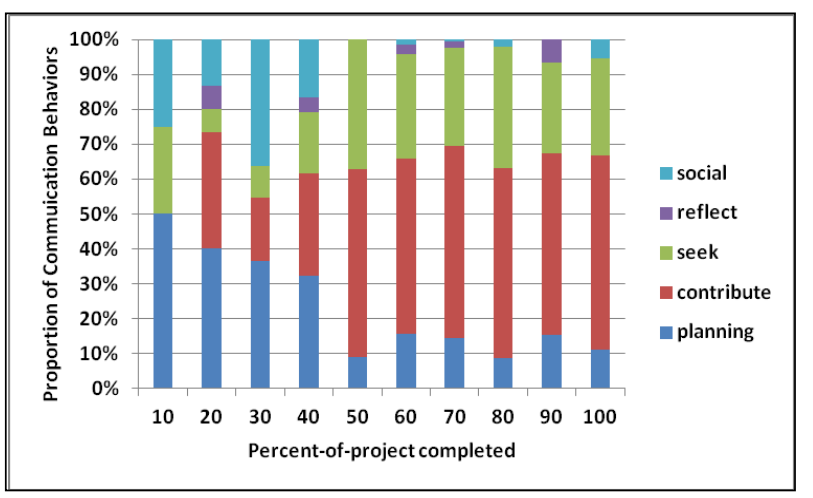

Figure 4. Proportion of Communication Behaviors for Leader Groups

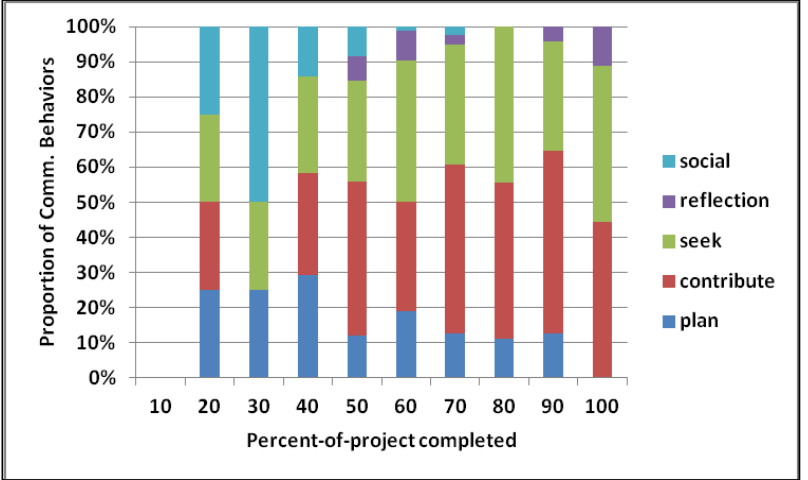

Figure 5. Proportion of Communication Behaviors for No-Leader Groups

within the group in the early stages of the project is reflected in the higher levels of planning behaviors during this phase of software development. Teams without leaders, on the other hand, tend to show more erratic patterns of planning, interspersed with seeking information and social interactions. In summary, the No-Leader teams seem to be always one time period behind the teams with Leaders, which seems to be true throughout the project.

\section{Comparison of Leaders, Followers, No-Leaders}

In order to understand more clearly the impact of leaders on the temporal patterns of the distributed teams, we separated the Leaders from their groups and looked at differences in temporal behaviors among Leaders, Followers within teams with leaders (now labelled as Followers), and No-Leader groups. Again, we looked at the proportion of communication behaviors in each time period for each group and compared the different proportions of temporal communication behaviors among the three groups. Not surprising, statistical tests indicate differences in the $40 \%(P=0.009$, Fisher exact test $)$, $50 \%(P=0.01$, Fisher exact test $)$, and 60\% $(P=0.01$, Fisher exact test) time periods. Figs. 6, 7, and 8 show the proportions of the communication behaviors that occurred within the Leader, Followers, and No-Leader groups.

Since the three periods $(40,50$, and 60\%) showed significant differences among the groups, we did a post-hoc pair-wise analysis to determine which specific communication behaviors were most similar/dissimilar. Table 1 presents the results of this comparison. In addition, Figs. 9, 10 and 11 provide a graphical view of the differences in the types of communication behaviors that were engaged in by the three groups for each of the time periods. The analysis indicates that groups differed in the $40 \%$ time period in their Seeking Input and Social Interaction behaviors. Leaders asked a higher proportion of questions than their followers, and Followers were more social than their Leaders. Seeking-input behaviors were again the distinguishing behavior among the groups in the $50 \%$ time period. Leaders spent a higher proportion of their time asking questions than either their Followers or No-Leader teams. Although not significant, Followers were engaged in more contributing behaviors at the $50 \%$ time period than either Leaders or No-Leader teams. At the same time, No-Leader teams were engaged in more reflecting and socializing behaviors at the $50 \%$ time period. Finally, and perhaps most importantly, both Leaders and their Followers are engaged in a 
higher proportion of contribution behaviors than students in the No-Leader teams during the $60 \%$ time period.

These results indicate that Leaders, Followers, and groups with No-Leaders have time variant differences in both the amount and kind of communications that they do within a software development project. Although not significant, Leaders clearly do more planning at the start of a project, than either Followers or No-Leader groups. Leaders then shift their behavior to asking questions and helping their Followers with various contributing tasks. The Leaders and Followers are in full contributing mode by the $60 \%$ time period, doing far more in this behavioral category than students in the No-Leader teams.

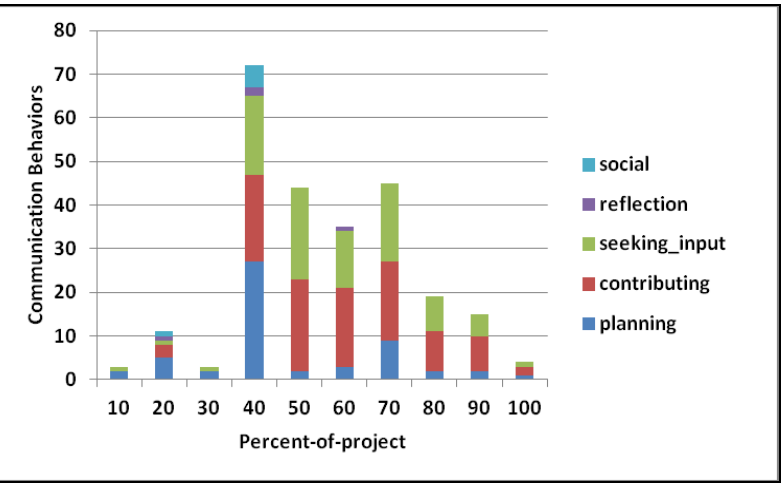

Figure 6. Proportion of Communication Behaviors for Leaders

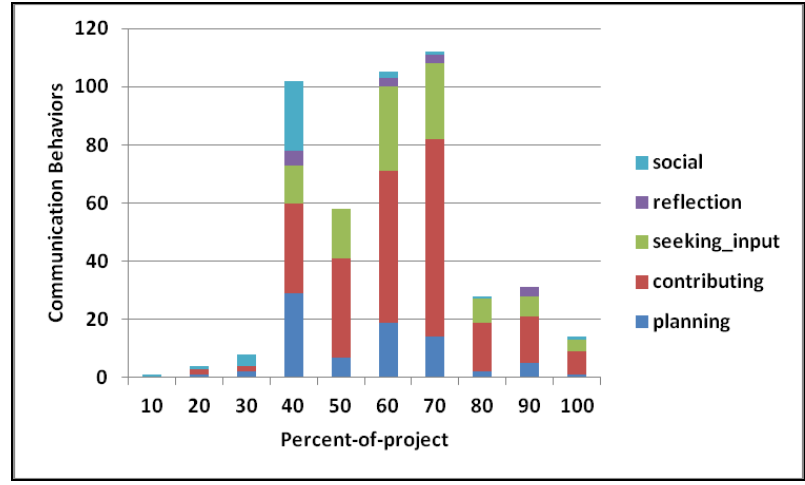

Figure 7. Proportion of Communication Behaviors for Followers

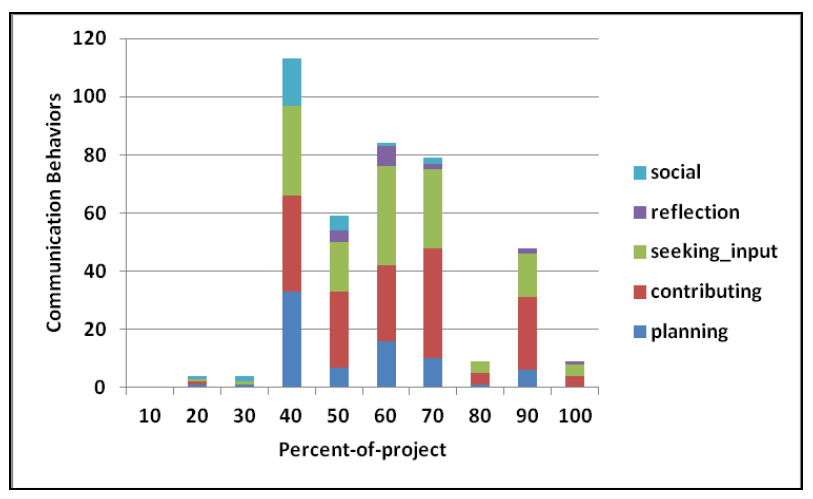

Figure 8. Proportion of Communication Behaviors for No-Leaders
TABLE I. COMPARISON OF PROPORTIONS AT DIFFERENT TIME PERIODS

\begin{tabular}{|l|l|l|l|l|}
\hline \multicolumn{2}{|l|}{$\begin{array}{l}\text { Communication } \\
\text { Behaviors }\end{array}$} & Leaders & Followers & $\begin{array}{l}\text { No- } \\
\text { Leaders }\end{array}$ \\
\hline $\mathbf{4 0 \%}$ & Seeking Input & & {$[2,3]^{*}$} & {$[3,2]^{*}$} \\
\cline { 2 - 5 } & Social Interaction & {$[1,3]^{*}$} & & {$[3,1]^{*}$} \\
\hline $\mathbf{5 0 \%}$ & Seeking Input & $\begin{array}{l}{[1,2]^{*}} \\
{[1,3]^{*}}\end{array}$ & {$[2,1]^{*}$} & {$[3,1]^{*}$} \\
\hline $\mathbf{6 0 \%}$ & Contributing & {$[1,3]^{*}$} & {$[2,3]^{*}$} & {$[3,1]^{*}$} \\
& & & & {$[3,2]^{*}$} \\
\hline
\end{tabular}

$* \mathbf{p}<.05$

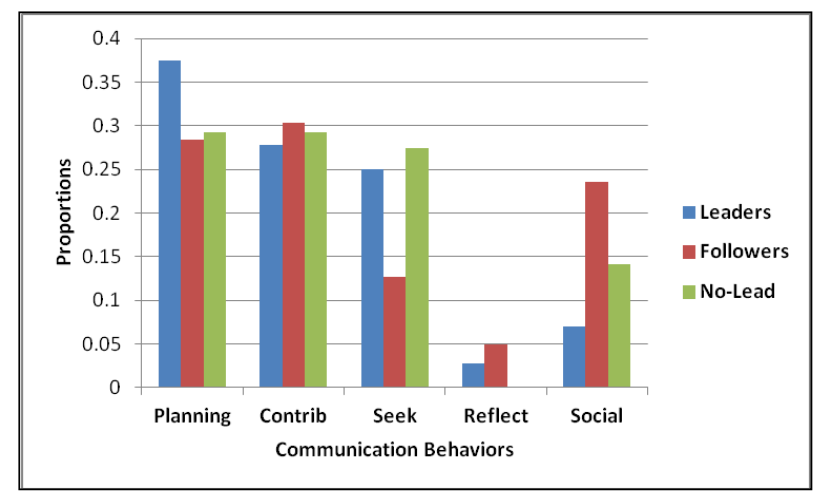

Figure 9. Comparison of Communication at $40 \%$ Time Period

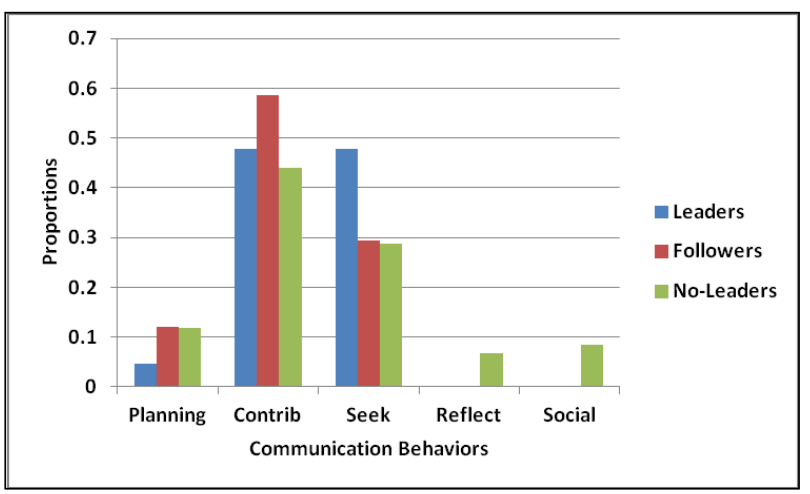

Figure 10. Comparison of Communication at $50 \%$ Time Period

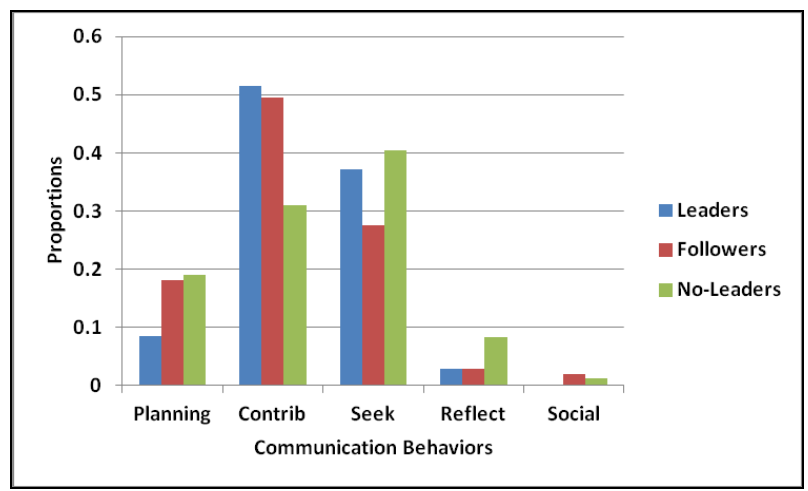

Figure 11. Comparison of Communication at $60 \%$ Time Period 


\section{DISCUSSION AND CONCLUSION}

The authors of this paper describe a method for analyzing the temporal communication behaviors of leaders (versus leaderless) global software development student teams. The method includes the application of a content analysis technique to transcripts of teams with and without leaders. Coded transcripts from these two groups were arranged in a temporal sequence of percent-of-project completion to determine the pair-wise variation among the behavioral communications of teams with and without leaders at different phases of the software development cycle. While Leader and No-Leader times had similar overall temporal patterns, teams with leaders had more communication in almost every temporal phase of the program development life cycle. There were also several distinguishing temporal patterns in the proportion of communication behaviors that occurred in Leader, Followers, and No-Leader groups. While there remain open questions about how to interpret these results, the findings indicate that temporal differences between Leaders and No-Leader groups do exist at different stages of the software development cycle. The authors also found some associations of temporal patterns of communication behaviors to different aspects of the software development process.

Leaders as "Completers." Schultz [29] first used the word "completer" as a way to describe the drive and intensity that a leader brings to a team. The data presented in this paper clearly show that teams with leaders started earlier and were immediately involved in planning, seeking input, and social behaviors (Fig. 4), as opposed to No-Leader teams that started later and had fewer planning behaviors (Fig. 5) at the beginning of the projects. The more intense activities that Leader teams had in the middle of the project also seems to support the notion that the presence of a leader helps distributed groups stay on task [22]. When examining the three types of groups (leaders, followers, and No-leaders), it becomes apparent that both the number and types of communications distinguish leaders from both their own followers and leaderless teams.

Seeking Input. It was somewhat surprising to find that the seeking input category was responsible for most of the temporal variations among groups in the 40 and $50 \%$ time phases. No-Leader groups asked a higher proportion of questions in the $40 \%$ time period (Fig. 6), but after separating the Followers from the Leader teams, it become clear that the differences among the groups were caused by Followers asking fewer questions (Table 1). The Leaders appear to continue to ask questions in the $50 \%$ time period. As several researchers note, asking questions tends to stimulate group discussion [45][46]. Thus a leader's questioning ability can both promote discussion on a specific topic as well as help integrate new information into a group's current knowledge base. Since the question-asking phase seems to have been followed by higher proportions of contributing behaviors by both Leaders and their Followers in the $60 \%$ time period, we can only conclude that a leader's questions may have led to a greater understanding of the problem's solution for group members.

Cyclical nature of projects. The authors began this study under the overarching assumption that teams work in cycles. This is a prominent theme in the team literature, which also suggests that teams work in recurring cycles of mutually dependent interaction [47][48]. To build on this, the authors focused on determining how the presence of a leader might affect these cycles. While both Leader and No-leader teams had similar overall temporal patterns, it was clear that the presence of a leader caused teams to start earlier, ask more questions in the middle part of the project, and follow this period with an increase in the number of contributing behaviors by both Leaders and their Followers. Again, when the groups are separated into respective leaders, followers, and no-leaders, there emerges distinct types of behaviors that distinguish leaders from other types of students. Our data seems to indicate that leaders provide key communication functions at the beginning and transition phases of a team project.

The results described in this paper extend research about distributed teams in several ways. For example, the current literature identifies a number of different temporal problems that a distributed team might encounter while doing work, but it does not define specific types of behaviors that can arise or how these behaviors might vary over the course of a project. Understanding how these behaviors affect a team is central to effectively managing temporal coordination among team members. This study suggests that seeking input behaviors may be an underlying mechanism that affects the temporal patterns of teams. The results of the current research also point to the relevance of leaders and their importance in shaping and managing the temporal behaviors in teams. In addition, although many have discussed the existence of cycles within a team, this research tries to determine how different members of a team may be responsible for these cycles. Our results point to a team's leader as a key player in the synchronization and coordination of temporal behaviors. By acknowledging that the management of teams is often the responsibility of the team leader, the current study integrates temporal research with the leadership literature.

\section{ACKNOWLEDGEMENTS}

This material is based upon work supported by the National Science Foundation under Grant No. 0705638. Any opinions, findings, and conclusions or recommendations expressed in this material are those of the author(s) and do not necessarily reflect the views of the National Science Foundation. We also wish to thank the students who participated in the study, and the many colleagues who helped make this research possible.

\section{REFERENCES}

[1] S. Marissa L., W. Christopher W., S. Eduardo, and B. C. Shawn, "Leading One Another Across Time and Space: Exploring Shared Leadership Functions in Virtual Teams," Review of pevista de Psicología del Trabajo y de las Organizaciones, vol. 26, no. 1, pp. 3-17, 2010.

[2] A. C. Bluedorn and K. S. Jaussi, "Leaders, followers, and time," The Leadership Quarterly, vol. 19, no. 6, pp. 654-668, 2008.

[3] S. Furst, R. Blackburn, and B. Rosen, "Virtual team effectiveness: a proposed research agenda," Information Systems Journal, vol. 9, no. 4, pp. 249-269, Dec. 2001. 
[4] J. S. Lurey and M. S. Raisinghani, "An empirical study of best practices in virtual teams," Information \& Management, vol. 38, no. 8, pp. 523544, 2001.

[5] J. Hamm, "The Five Messages Leaders Must Manage," Harvard Business Review, Apr. 2006.

[6] B. P. Lientz and K. P. Rea, "Breakthrough technology project management," Sep. 1998.

[7] L. A. Hambley, T. A. O’Neill, and T. J. B. Kline, "Virtual team leadership: The effects of leadership style and communication medium on team interaction styles and outcomes," Organizational Behavior and Human Decision Processes, vol. 103, no. 1, pp. 1-20, 2007.

[8] A. C. Bluedorn and R. B. Denhardt, "Time and Organizations," Journal of Management, vol. 14, no. 2, pp. 299-320, Jun. 1988.

[9] D. L. Parnas, "On the criteria to be used in decomposing systems into modules," Communications of the ACM, vol. 15, no. 12, pp. 1053-1058, 1972.

[10] J. Colazo, "Following the Sun: Temporal Dispersion and Performance in Open Software Project Teams," Journal of the Association for Information Systems, vol. 11, no. Special Issue, pp. 684-707, Nov. 2010.

[11] K. Swigger, M. Hoyt, F. C. Serce, V. Lopez, and F. N. Alpaslan, "The temporal communication behaviors of global software development student teams," Computers in Human Behavior, vol. 28, no. 2, pp. 384392, Mar. 2012

[12] F. C. Serce, R. Brazile, K. Swigger, G. Dafoulas, F. N. Alpaslan, and V. Lopez, "Interaction patterns among global software development learning teams," 2009, pp. 123-130.

[13] I. Brooks and K. Swigger, "Using Sentiment Analysis to Measure the Effects of Leaders in Global Software Development Teams," International Conference on Collaboration Technolgies and Systems, May 2012.

[14] M. S. Poole and J. Roth, "Decision Development in Small Groups V Test of a Contingency Model," Human Communication Research, vol. 15, no. 4, pp. 549-589, Jun. 1989.

[15] S. Farmer, "Time Enough to Work: Employee Motivation and Entrainment in the Workplace," Time \& Society, vol. 13, no. 2-3, pp. 265-284, Sep. 2004.

[16] C. J. G. Gersick, "Time and transition in work teams: Toward a new model of group development," Academy of management journal, pp. 9$41,1988$.

[17] [17] D. I. Ballard, F. Tschan, and M. J. Waller, "All in the Timing Considering Time at Multiple Stages of Group Research," Small Group Research, vol. 39, no. 3, pp. 328-351, Jun. 2008.

[18] F. J. Landy, H. Rastegary, J. Thayer, and C. Colvin, "Time urgency: The construct and its measurement.," Journal of Applied Psychology, vol. 76, no. 5, pp. 644-657, 1991.

[19] S. Mohammed, K. Hamilton, and A. Lim, "The incorporation of time in team research: Past, current, and future," Team effectiveness in complex organizations: Cross-disciplinary perspectives and approaches, pp. 321-348, 2009.

[20] F. Spillers, "Synch with me': Rhythmic interaction as an emerging principle of experiential design.," in Hekkert, PM et. al. in the Proceedings of the Sixth Bi-annual Conference on Design and Emotion. Hong Kong, China. Accessed December 2nd, 2009.

[21] M. A. Marks, J. E. Mathieu, and S. J. Zaccaro, "A temporally based framework and taxonomy of team processes," Academy of Management Review, pp. 356-376, 2001.

[22] J. E. McGrath and A. B. Hollingshead, "Groups interacting with technology: Ideas, evidence, issues, and an agenda.," 1994.

[23] D. Ancona and C.-L. Chong, "Cycles and synchrony: The temporal role of context in team behavior.," 1999.

[24] B. J. C. Claessens, W. van Eerde, C. G. Rutte, and R. A. Roe, “A review of the time management literature," Personnel Review, vol. 36, no. 2, pp. 255-276, 2007.

[25] Q. R. Jett and J. M. George, "Work interrupted: A closer look at the role of interruptions in organizational life," Academy of Management Review, vol. 28, no. 3, pp. 494-509, 2003.
[26] L. L. Martins, L. L. Gilson, and M. T. Maynard, "Virtual Teams: What Do We Know and Where Do We Go From Here?," Journal of Management, vol. 30, no. 6, pp. 805-835, Dec. 2004.

[27] L. A. Perlow, "Time to Coordinate Toward an Understanding of WorkTime Standards and Norms in a Multicountry Study of Software Engineers," Work and Occupations, vol. 28, no. 1, pp. 91-111, Feb. 2001.

[28] J. B. Carson, P. E. Tesluk, and J. A. Marrone, "Shared leadership in teams: An investigation of antecedent conditions and performance," The Academy of Management Journal ARCHIVE, vol. 50, no. 5, pp. $1217-$ 1234, 2007.

[29] W. C. Schutz, "On group composition.," The Journal of Abnormal and Social Psychology, vol. 62, no. 2, pp. 275-281, 1961.

[30] S. A. Wheelan and F. Johnston, "The Role of Informal Member Leaders in a System Containing Formal Leaders," Small Group Research, vol. 27, no. 1, pp. 33-55, Feb. 1996.

[31] R. J. Ocker, H. Huang, R. Benbunan-Fich, and S. R. Hiltz, "Leadership Dynamics in Partially Distributed Teams: an Exploratory Study of the Effects of Configuration and Distance," Group Decision and Negotiation, vol. 20, no. 3, pp. 273-292, Nov. 2009.

[32] T. Kayworth and D. Leidner, "The global virtual manager: a prescription for success," European Management Journal, vol. 18, no. 2, pp. 183 194, Apr. 2000.

[33] S. Weisband, "Maintaining awareness in distributed team collaboration: Implications for leadership and performance," in Distributed work, P. Hinds S. Kiesler, Ed. Cambridge, MA, US: MIT Press, 2002, pp. 311333.

[34] Y. Yoo and M. Alavi, "Emergent leadership in virtual teams: what do emergent leaders do?," Information and Organization, vol. 14, no. 1, pp. 27-58, 2004.

[35] Y. Yoo and M. Alavi, "Electronic mail usage pattern of emergent leaders in distributed teams," 2002.

[36] N. I. Misiolek and R. Heckman, "Patterns of emergent leadership in virtual teams," in System Sciences, 2005. HICSS'05. Proceedings of the 38th Annual Hawaii International Conference on, 2005, p. 49a-49a.

[37] G. Koutsides, "Using cooperative learning in design and technology," Journal of Design \& Technology Education, vol. 6, no. 1, 2009.

[38] P. Bouillon, J. Krinke, and S. Lukosch, "Software engineering projects in distant teaching," 2005. [Online]. Available: https://vpn2.unt.edu/+CSCO+0h756767633A2F2F71766670626972656 C2E6870792E6E702E6878++/191940/. [Accessed: 03-Jul-2012].

[39] D. Damian, J. Chisan, L. Vaidyanathasamy, and Y. Pal, "Requirements engineering and downstream software development: Findings from a case study," Empirical Software Engineering, vol. 10, no. 3, pp. 255283, 2005 .

[40] J. Y. K. Lim and L. Chidambaram, "A Longitudinal Comparison of Leader-Follower Relationships between High and Low Performing SelfManaged Work Teams in Virtual Settings," in System Sciences (HICSS), 2011 44th Hawaii International Conference on, 2011, pp. 1-10.

[41] Lawrence, S. and Atlee, J., Software Engineering: Theory and Practice, Third. New Jersey: Pearson, Pretice Hall, 2006.

[42] S. J. Zaccaro, A. L. Rittman, and M. A. Marks, "Team leadership," The Leadership Quarterly, vol. 12, no. 4, pp. 451-483, 2002.

[43] D. D. Curtis and M. J. Lawson, "Exploring collaborative online learning," Journal of Asynchronous learning networks, vol. 5, no. 1, pp. 21-34, 2001.

[44] A. P. Massey, M. M. Montoya-Weiss, Y. T. Hung, and others, "Because time matters: Temporal coordination in global virtual project teams," Journal of management information systems, vol. 19, no. 4, pp. 129 156, 2003.

[45] K. Crowston, A. Wiggins, and J. Howison, "Analyzing leadership dynamics in distributed group communication," in System Sciences (HICSS), 2010 43rd Hawaii International Conference on, 2010, pp. 110 .

[46] R. Huang, S. Kahai, and R. Jestice, "The contingent effects of leadership on team collaboration in virtual teams," Computers in Human Behavior, vol. 26, no. 5, pp. 1098-1110, 2010 
[47] F. P. Morgeson, D. S. DeRue, and E. P. Karam, "Leadership in Teams: A Functional Approach to Understanding Leadership Structures and Processes," Journal of Management, vol. 36, no. 1, pp. 5-39, Jan. 2010.
[48] M. Flammia, Y. Cleary, and D. M. Slattery, "Leadership Roles, Socioemotional Communication Strategies, and Technology Use of Irish and US Students in Virtual Teams," IEEE Transactions on Professional Communication, vol. 53, no. 2, pp. 89-101, Jun. 2010. 